\title{
Supply optimization based on society's cost of electricity and a calibrated demand model for future renewable energy transition in Niger
}

\author{
Fitsum Bekele Tilahun ${ }^{1}$, Ramchandara Bhandari ${ }^{1 *}$ (D) and Mengesha Mamo²
}

\begin{abstract}
Background: In an attempt to realize the most beneficial and optimal mix of electricity generation in Niger, a society's cost of electricity (SCOE) as the levelized cost of electricity (LCOE) plus the cost of climate change and air pollution is formulated. The SCOE is used as a basis for setting the performance criteria for supply optimization to balance future electricity demand in Niger. The demand projection is derived from a system dynamics model that anticipates future changes based on its influencing factors of population growth, urbanization progress, and industrial development.
\end{abstract}

Results: Reference case and what-if scenarios are simulated to see the projected electricity demand and possible renewable energy transition pathways. As a result, for example, the annual electricity of 3214 GWh estimated for 2030 might be balanced with about $200 \mathrm{MW}, 104 \mathrm{MW}, 85 \mathrm{MW}$, and $63 \mathrm{MW}$ power from hydropower, grid-tied PV, coal, and diesel for SCOE optimized grid. For the same case, a greenhouse gas (GHG) emission reduction of 11.26$15.66 \%$ could be achieved when compared to the LCOE-based optimized grid. In addition, the most preferred energy option hydropower will be almost exhausted when the projected electricity demand in 2035 reaches slightly more than double its value in 2025. Thus, Niger should start exploiting its solar as well as conventional sources intensively to balance its future energy demand.

Conclusions: In this work, a mixed energy grid is optimized primarily on affordability while considering its sustainability. The implemented holistic approach lessens the need for energy import in the country and provides relief to energy security issues such as electricity price volatility and supply reliability. Additionally, the proposed strategy helps to guide the renewable energy transition pathway in Niger.

Keywords: Electricity demand projection, Supply optimization, Society's cost of electricity (SCOE), Levelized cost of electricity (LCOE), Renewable energy transition, Niger

\section{Background}

The provision of low-cost energy to the rural and periurban areas and reliable energy access to the urban and industrial sector are an integral part of Niger's development plan [1]. Nevertheless, the realization of this plan has been hindered by three related challenges. First, the inadequate understanding of the underlying relation

\footnotetext{
* Correspondence: ramchandra.bhandari@th-koeln.de

${ }^{1}$ Institute for Technology and Resources Management in the Tropics and Subtropics (ITT), TH Köln (University of Applied Science), Betzdorfer Strasse 2, 50679 Cologne, Germany

Full list of author information is available at the end of the article
}

among energy demand and its influencing factors (population growth, industrialization, and urban progress) for balancing supply and demand in developing countries such as Niger [2, 3]. For instance, with Niger's population in 2017 being around 21.48 million [4], the per capita electricity consumption was around $51 \mathrm{kWh}$, compared to the African average of $780 \mathrm{kWh}$ and West African average of $186 \mathrm{kWh}$ (Fig. 1) [5]. Although the past trend of electricity consumption in Niger has been changing slowly, it is expected to increase significantly

(c) The Author(s). 2019 Open Access This article is distributed under the terms of the Creative Commons Attribution 4.0 International License (http://creativecommons.org/licenses/by/4.0/), which permits unrestricted use, distribution, and reproduction in any medium, provided you give appropriate credit to the original author(s) and the source, provide a link to the Creative Commons license, and indicate if changes were made. 


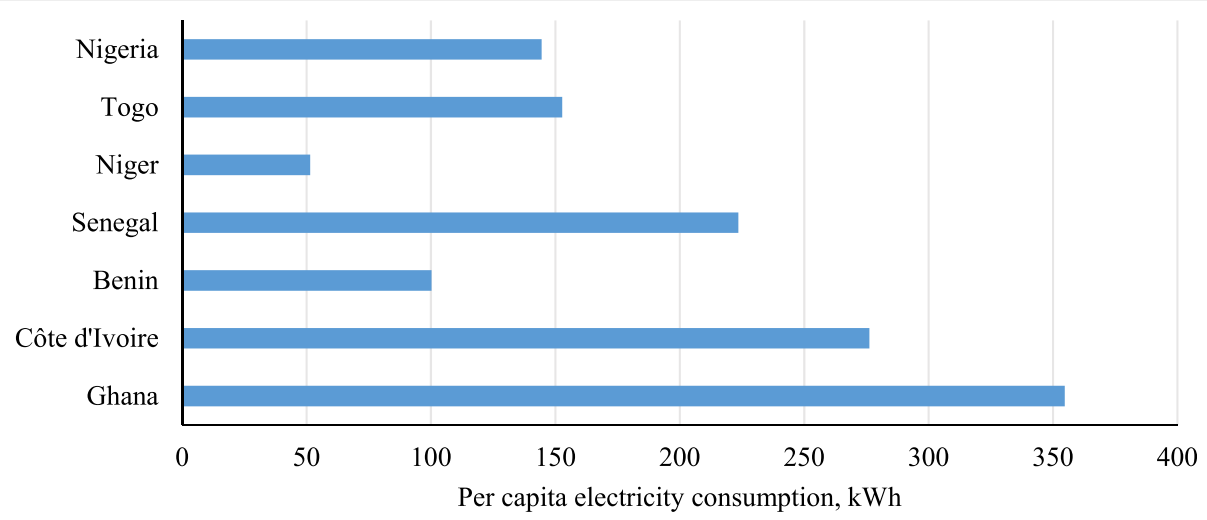

Fig. 1 Per capita electricity consumption of Niger in comparison with selected West African countries in 2017

in the coming years due to a high annual population growth of about $3.3 \%$.

The relationship between economic development and increased energy demand [3, 6-8] as well as the strong correlation between urbanization and enhanced energy utilization [3, 6, 8-11] are clearly observed in the literature. These trends are also accompanied with a relative political stability and large-scale investments in the mining and oil sector of a country, which is also evident in Niger. Often, economic development reciprocates into increased energy consumption by the industrial and urban sectors. Thus, the development of a valid model that translates and anticipates quantitatively these related events would help energy policymakers to realize the development goals.

The second challenge that hinders the provision of low-cost and reliable energy is a heavy reliance on imported electricity from Nigeria, which poses serious energy security issues in Niger [12]. According to Société Nigérienne d'Electricité (NIGELEC, Niger's electricity company), the share of imported energy reached $86.5 \%$ in 2017 purchased at about $0.044 \$ / \mathrm{kWh}$ and sold at an average price of $0.158 \$ / \mathrm{kWh}$ [13]. As can be seen from Fig. 2, the imported electricity from Nigeria has significantly increased over recent years. Under the existing electricity purchase price, there is hardly any room for renewable energy (RE) participation in the fossil dominated grid. However, this share of cheap imported energy is expected to decrease significantly in the coming years, due to the energy crisis in Nigeria caused by the inability to meet the energy demands of its growing population and economy [14, 15]. This has been a major factor compelling the Nigerian government to launch an electricity market reform resulting in an increased electricity selling price. Moreover, Nigeria's old refineries and inefficient single cycle turbines might have contributed to the reduced availability of power export to Niger [15].

Finally, the absence of an energy mix in the power grid based on the availability and cost of generation (including the cost on the environment), which has led to an inefficient fossil dominated power generation, is another challenge to the provision of low-cost and reliable energy in Niger. Apart from an estimated 2\% solar photovoltaic (PV) installation in the telecom and off-grid sectors, power generation in the country still relies entirely on fossil fuels (coal and diesel) [12, 13]. Moreover, many of NIGELEC's diesel power plants are close to the

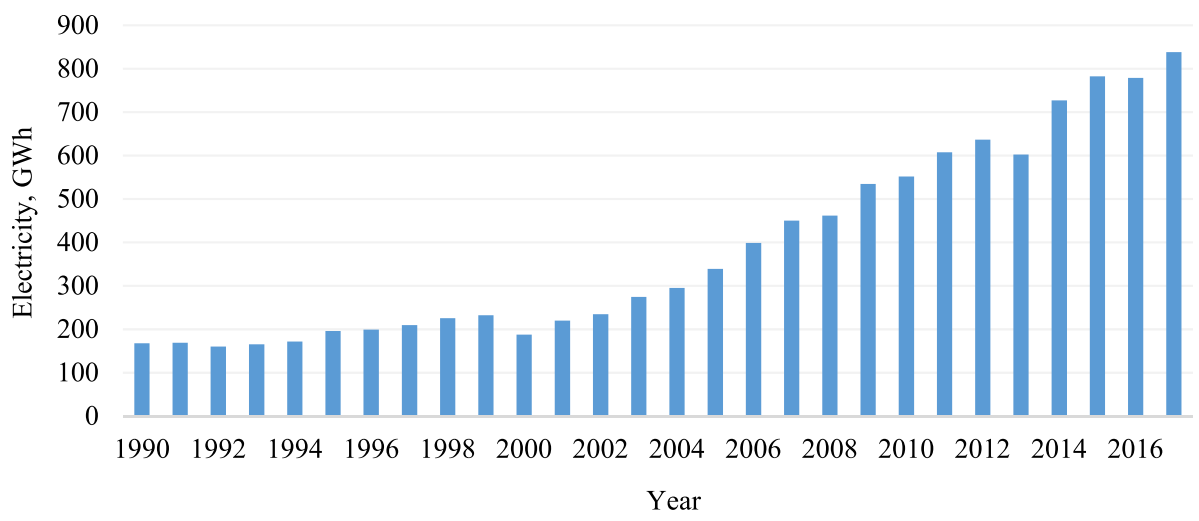

Fig. 2 Electricity import to Niger (based on NIGELEC database) [13] 


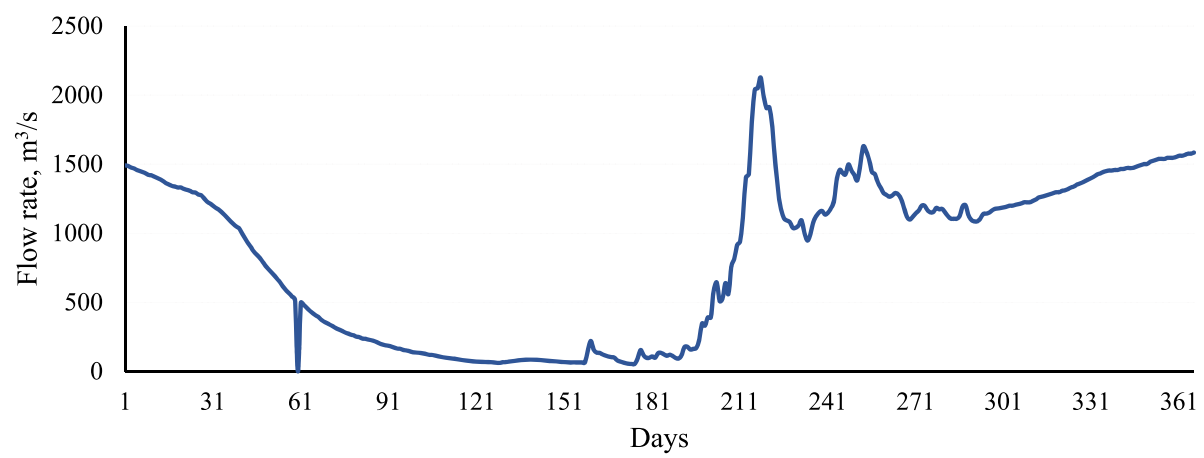

Fig. 3 Flow rate of Niger River in 2015 [16]

decommissioning phase but continue to operate with high generation costs [13].

Against this backdrop, solar PV and hydropower hold the promise of becoming suitable alternative energy sources in Niger. An attractive medium to large hydropower potential in the country is estimated at about 312-450 MW [17, 18]. Until now, only a feasible potential assessment has been carried out for a few sites, such as Dyodyonga, Gambou, and Kandadji, with an estimated hydroelectric power potential of about 38, 122.5, and $125 \mathrm{MW}$, respectively [17]. Figure 3 depicts the flow rate of the Niger River in dry and wet seasons measured in Niamey [16]. Some suitable mini-hydropower sites have also been identified along four tributaries of the Niger River, namely Mekrou, Tapoa, Gorouol, and Sirba, amounting to a combined capacity of 3-8 MW $[17,18]$.

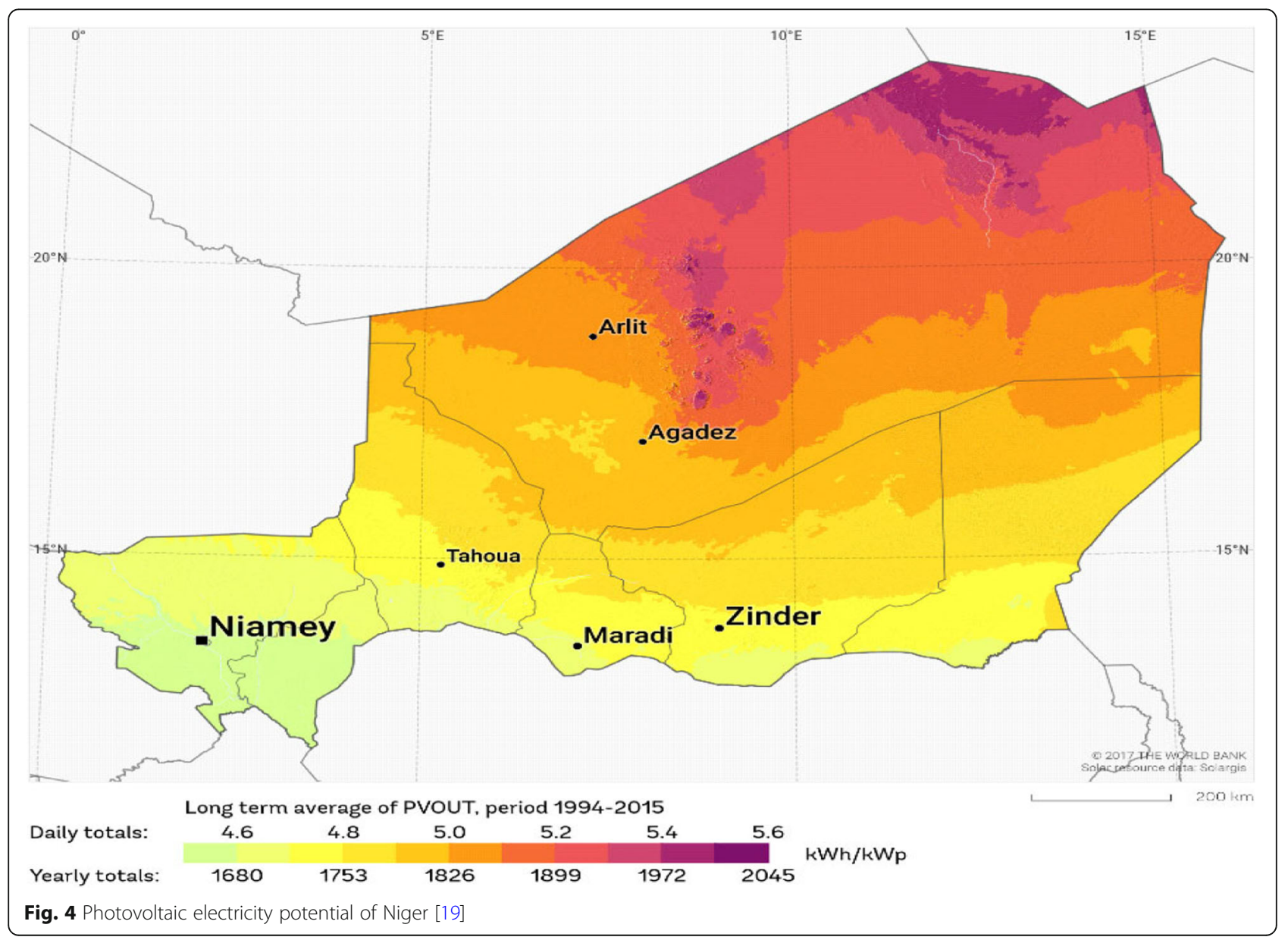




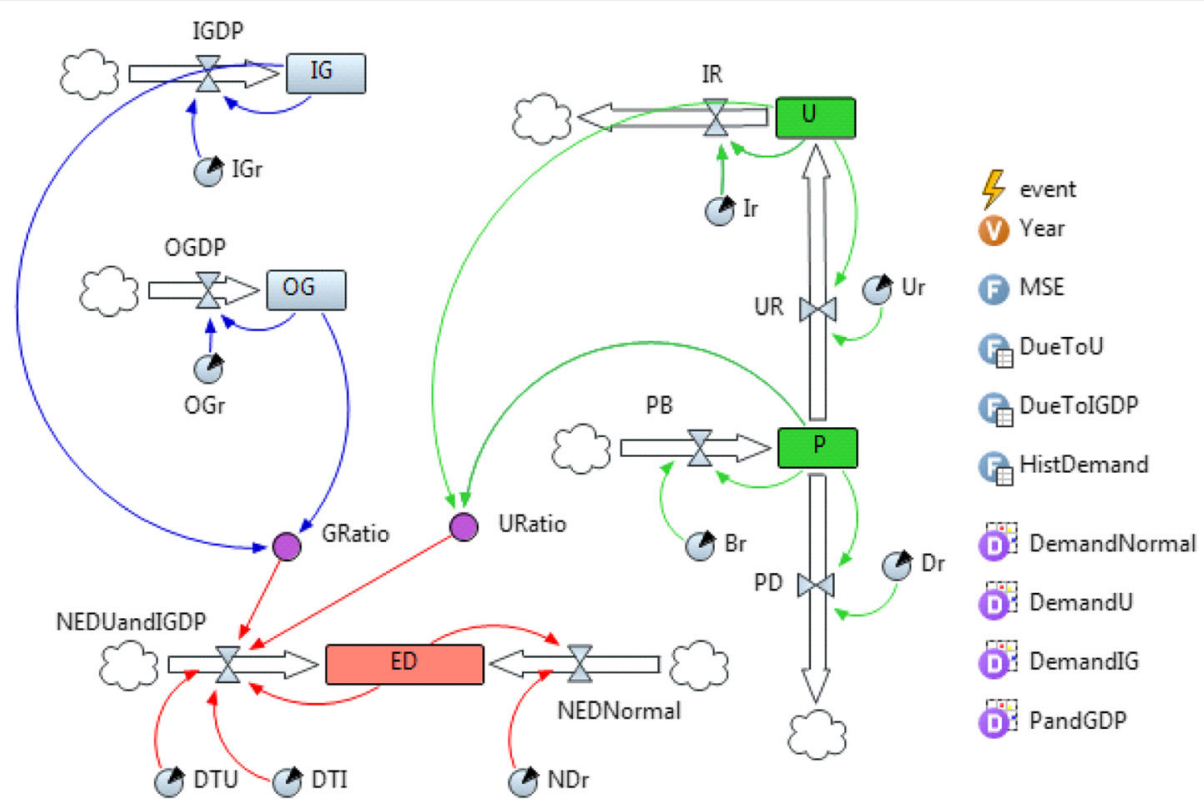

Fig. 5 Electricity demand model in the Anylogic using system dynamics

Niger is also endowed with a high solar PV potential. As shown in Fig. 4, almost all regions in the country have a daily average PV potential of over $4.6 \mathrm{kWh} / \mathrm{kWp}$ [19]. Thus, if properly designed and operated, power from grid-tied PV systems could provide an efficient method of harvesting the available solar power.

A potential assessment that has been carried out in Niger so far indicates that wind resource is negligible [18]. It also showed that conventional sources of energy such as diesel and coal are abundant in the country [20]. Considering these findings and the aforementioned energy-related issues, a holistic approach for finding an optimal energy mix based on the availability and cost of generation (including the cost to the environment) would be necessary and insightful. Moreover, this approach should balance the future energy demand and include a strategy to lessen the need for imported energy. Therefore, the optimal energy mix criteria should be based on the following trade-offs:

- The complementary nature of solar and hydropower should be used to compensate for the lower energy output from hydropower during the dry season.

- The high electricity generation cost from solar PV, which has not yet reached a level to be competitive with hydropower, and abundant conventional power sources should be balanced.

- Power from conventional sources should be used to match the future energy demand but lessen their negative impact on climate change and air pollution.

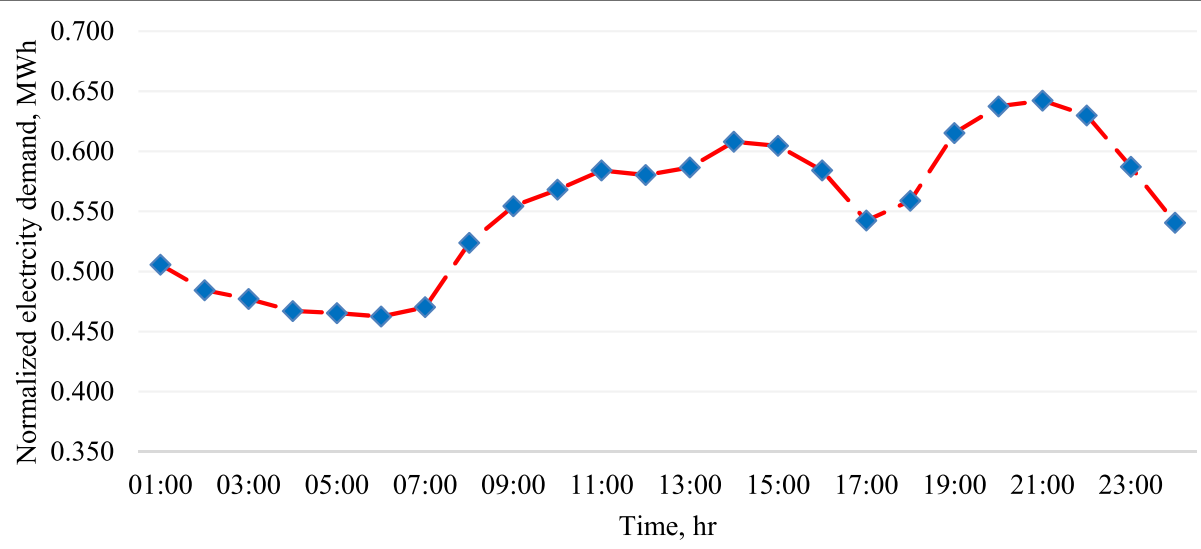

Fig. 6 The normalized electricity demand profile for Niger from the NIGELEC database 
Table 1 Overview of parameter values used to determine the efficiency of a PV system

\begin{tabular}{lll}
\hline Parameter & Value & Source \\
\hline$P_{p}$ & $130 \mathrm{~W} / \mathrm{m}^{2}$ & {$[21]$} \\
$a$ & $-0.0047 \mathrm{~K}^{-1}$ & {$[22]$} \\
$p_{0}$ & 0.0072 & {$[23]$} \\
$\eta_{\mathrm{AC}, c}$ & $99 \%$ & {$[22]$} \\
$\eta_{\mathrm{DC}, c}$ & $99 \%$ & {$[22]$} \\
$\eta_{d}$ & $98.5 \%$ & {$[22]$} \\
$\eta_{\mathrm{di}}$ & $99 \%$ & {$[22]$} \\
$\eta_{m}$ & $98 \%$ & {$[22]$} \\
\hline
\end{tabular}

Similarly to the indications given in [24, 25], all future electricity generation schemes should be designed according to the specific context of the country. Considering how poor most developing countries such as Niger are, a policy that ensures a mixed energy grid that is primarily based on affordability and has an eye on sustainability should be the main aim in designing optimal energy supply systems. Therefore, the specific objectives of the study are

- To develop Niger's future energy demand based on its influencing factors of population growth, industrialization, and urbanization progress.

- To calibrate the model against historical data.

- To formulate and optimize a supply model for an optimal mix of conventional and renewable energy sources based on the LCOE and SCOE.

- To simulate future renewable energy transition scenarios in Niger.

\section{Methods}

The model employed in this study consists of three main components: electricity demand projection, supply, and optimization model. The following sections give the details of these components.

\section{Electricity demand model}

Several studies were conducted for short or/and longterm electricity demand projection that can be

Table 2 Parameter values used in the supply model and calculation of LCOE for setting the optimization weights [26, 27]

\begin{tabular}{lllll}
\hline Parameter & Grid-tied PV & Hydropower & Coal & Diesel \\
\hline Capital cost, \$/kW & 2400 & 2100 & 1300 & 1250 \\
Life time, year & 20 & 40 & 40 & 20 \\
Capacity factor, \% & 21 & 65 & 70 & 60 \\
O\&M cost, \$/kW/year & 24 & 55 & 45 & 10 \\
Fuel cost, \$/Mbtu & - & - & 5.1 & 18.23 \\
Heat rate, btu/KWh & - & - & 8937 & 10,000 \\
\hline
\end{tabular}

Table 3 Greenhouse gas (GHG) emission rates for various power-generation technologies considered [28]

\begin{tabular}{ll}
\hline Technology & $\mathrm{GHG}$ emissions rates $\left(\mathrm{kg} \mathrm{CO}_{2} \mathrm{eq} / \mathrm{MWh}\right)$ \\
\hline Hydroelectric facility & $0.5-152$ \\
Natural gas-fired power plant & $400-500$ \\
Oil-fired power plant & $790-900$ \\
Coal-fired power plant & $900-1200$ \\
\hline
\end{tabular}

categorized into six types: regression based [29], autoregressive integrated moving average (ARIMA) [30], artificial neural networks [31], fuzzy logic [32], support vector [33], and system dynamics models [34]. The system dynamics approach is able to handle the dynamic evolution of vital energy forecasting variables with feedback loops among each other [35] and allows the incorporation of stochastic behavior [36].

In this work, the inherent relationship between energy demand and economic and social variables is studied using the system dynamics approach. The model anticipates potential electricity demand changes in Niger based on its influencing factors. The following valid assumptions are considered in the system dynamics modeling:

- Due to limited electricity consumption data for Niger (less than a couple of decades), the electricity demand projection is carried out for a short period of up to 2035.

- In Niger's context, three influencing factors that may strongly affect electricity consumption are included in the model. The first factor is the normal electricity demand due to the change in total population each year. The second influence comes from the effect of urbanization determined from the ratio of the urban population to the total population every year. Lastly, the industrialization change observed each year also influences electricity demand. Electricity demand due to industrialization can be determined from the ratio of other GDPs and industrial GDP in Niger. Other GDPs are defined in this work as GDPs related to service and agricultural economic activities.

- The net change in electricity demand each year from the previous year due to the aforementioned influences can be represented by a linear function [37].

Table 4 Overview of the climate change and air pollution cost used in calculating the SCOE

\begin{tabular}{llll}
\hline Cost & Natural gas & Diesel & Coal \\
\hline COCC, Cents/kWh & 0.36 & 0.49 & 0.71 \\
COAP, Cents/kWh & 0.21 & 1.3 & 2.42 \\
\hline
\end{tabular}


Table 5 Calibrated parameter values of the electricity demand model

\begin{tabular}{llllllll}
\hline $\begin{array}{l}\text { Calibrated } \\
\text { parameters }\end{array}$ & DTU & DTI & ND $_{r}$ & $a_{1,1}$ & $a_{1,2}$ & $a_{0,1}$ & $a_{0,2}$ \\
\hline Value & 0.0004 & 0.0480 & $4.349 \mathrm{E}$ & 1.1455 & - & - & 1.5999 \\
& & & -4 & & 0.0027 & 1.2352 & \\
\hline
\end{tabular}

Accordingly, each year's net electricity demand (NED) in Niger can be determined from the rate of change of total electricity demand (ED) as

$$
(\mathrm{ED}) / \mathrm{dt}=\mathrm{NED}
$$

The NED is the sum of the product of the previous year's electricity demand by the normal demand rate (NDr) and the newly added electricity demand rate (ADr) due to urbanization and industrialization progress calculated by

$$
\begin{aligned}
& \mathrm{NED}=\mathrm{ED} \cdot\left(\mathrm{ND}_{r}+\mathrm{AD}_{r}\right) \\
& \mathrm{AD}_{r}=\mathrm{DTU} \cdot \mathrm{UF}+\mathrm{DTI} \cdot \mathrm{IF}
\end{aligned}
$$

where UF and IF are the urbanization and industrialization factors that affect the net electricity demand due to changes in previous year's urbanization and industrialization, respectively. DTU and DTI are the urbanization and industrialization coefficients. UF and IF are represented by a functional relation of urban population $(U)$ to the total population $(P)$ ratio and other GDP (OG) to the industrial GDP (IG) ratio as

$$
\begin{aligned}
& \mathrm{UF}=(\mathrm{U} / \mathrm{P}) \\
& \mathrm{IF}=(\mathrm{OG} / \mathrm{IG})
\end{aligned}
$$

where $f$ is a linear function given by

$$
(\mathrm{x})=\mathrm{a} 1+\mathrm{a} 0, i
$$

where the coefficients in Eq. (4) are determined from the model calibration experiment based on historical data.
On the other hand, the population and urban dynamics in each year of Eq. (3a) can be represented as

$$
\begin{aligned}
& (\mathrm{P}) / \mathrm{dt}=\mathrm{PB}-\mathrm{PD} \\
& (\mathrm{U}) / \mathrm{dt}=\mathrm{UR}-\mathrm{IR}
\end{aligned}
$$

where the total births (PB), total deaths (PD), urbanization rate (UR) and immigration rate (IR) in the current year can be determined as

$$
\begin{aligned}
& \mathrm{PB}=P \cdot B_{r} \\
& \mathrm{PD}=P \cdot D_{r} \\
& \mathrm{UR}=U \cdot U_{r} \\
& \mathrm{IR}=U \cdot I_{r}
\end{aligned}
$$

where $\mathrm{Br}, \mathrm{Dr}, \mathrm{Ur}$, and Ir are birth rate, death rate, urbanization rate, and immigration rate, respectively.

Similarly, the GDP dynamics can be represented as

$$
\begin{aligned}
& (\mathrm{IG}) / \mathrm{dt}=\mathrm{IGDP} \\
& (\mathrm{OG}) / \mathrm{dt}=\mathrm{OGDP}
\end{aligned}
$$

where

$$
\begin{aligned}
& \mathrm{IGDP}=\mathrm{IG}_{r} \cdot \mathrm{IG} \\
& \mathrm{OGDP}=\mathrm{OG}_{r} \cdot \mathrm{OG}
\end{aligned}
$$

where OG and IG are industrial and other GDP growth rates in Niger.

The dynamics given in Eqs. (1-8) are based on two sub-dynamics computed from the previous year's change in model variables. Considering urbanization and industrialization growth rates as negligible, the net electricity demand observed will only be based on the normal population growth in the country. The normal demand rate $\left(\mathrm{ND}_{r}\right)$ captures these dynamics. As the urbanization and industrialization growth rates present the change, the net electricity demand will also reflect this change through the UF and IF evolving parameter values. These changes are modeled as a functional value

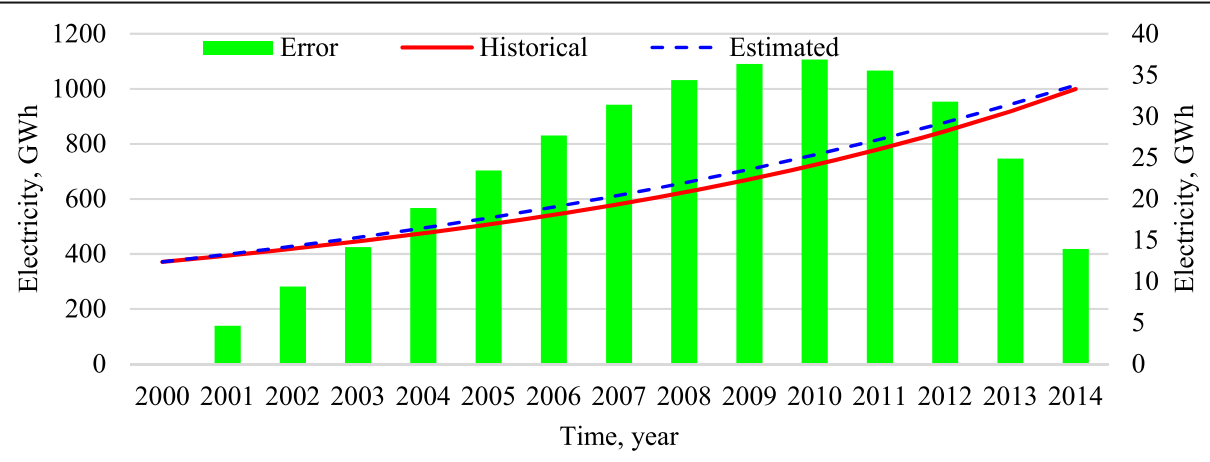

Fig. 7 Calibrated electricity demand model output vs. measured historical data 
Table 6 Projected electricity demand in Niger from 2019 to 2050

\begin{tabular}{llll}
\hline Year & $\begin{array}{l}\text { Electricity demand, } \\
\text { GWh }\end{array}$ & $\begin{array}{l}\text { Population, million } \\
\text { person }\end{array}$ & $\begin{array}{l}\text { GDP, billion } \\
\text { USD }\end{array}$ \\
\hline 2019 & 1452.417 & 22.87 & 9.42 \\
2020 & 1560.967 & 23.59 & 9.89 \\
2021 & 1677.672 & 24.34 & 10.39 \\
2022 & 1803.147 & 25.11 & 10.92 \\
2023 & 1938.055 & 25.90 & 11.48 \\
2024 & 2083.108 & 26.72 & 12.06 \\
2025 & 2239.073 & 27.56 & 12.67 \\
2026 & 2406.775 & 28.43 & 13.32 \\
2027 & 2587.102 & 29.32 & 13.99 \\
2028 & 2781.009 & 30.24 & 14.70 \\
2029 & 2989.525 & 31.18 & 15.45 \\
2030 & 3213.755 & 32.16 & 16.24 \\
2031 & 3454.889 & 33.16 & 17.07 \\
2032 & 3714.209 & 34.19 & 17.94 \\
2033 & 3993.094 & 35.25 & 18.86 \\
2034 & 4293.026 & 36.34 & 19.82 \\
2035 & 4615.603 & 37.46 & 20.83 \\
\hline & & &
\end{tabular}

of a linear function that takes on the ratios that quantify urbanization $(U / P)$ and industrialization $(\mathrm{OG} / \mathrm{IG})$.

The above dynamics given in Eqs. (1-8) is coded into the Anylogic 8.3.2 software resulting in the system dynamics model depicted in Fig. 5. Finally, this model is calibrated against the historical electricity demand data and will be explained in the "Results and discussions" section.

The Anylogic computational platform was chosen because it is an object-oriented modeling framework suitable for system dynamics. Moreover, the Anylogic has a meta-heuristics optimization engine based on the OptQuest package from OptTek Systems that allow parameter variation experiments, calibration of parameters, optimization, and Monte-Carlo runs to be carried out.

Finally, the hourly electricity demand for a given year can be determined from the product of the normalized hourly load profile and annual electricity demand estimate (from the system dynamics model). Figure 6 shows the normalized hourly load profile obtained from the NIGELEC database.

\section{Electricity supply model}

Apart from an estimated 2\% PV installation in the telecom and off-grid sectors, the power generation in Niger entirely relies on fossil fuels (coal and diesel) [12]. The existing grid capacity is about $173 \mathrm{MW}$ contributed from the five companies NIGELEC, SORAZ, SONICHAR, AGGREKO, and SOMINA. Additionally, there are some fragmented companies supplying power to mining sites. With a share of about half of the total power production, NIGELEC is the main company responsible for the production, transmission, and distribution of electricity in the country [13]. NIGELEC operates inefficiently and shortly before decommissioning power plants with high operating costs [12], the said inefficient power plants partly contribute to the relatively high electricity selling price (in the range of about 0.16 and $0.22 \$ / \mathrm{kWh}$ ) despite a very low electricity import price of around 0.044 $\$ / \mathrm{kWh}[13]$.

In this study, it is assumed that the future electricity supply will be contributed both from RE and conventional sources. Grid-tied PV and hydropower represent the RE generation. Hydropower is a cost-efficient electricity generation technology [38] capable of responding quickly to demand fluctuation [38, 39], and solar PV can complement its seasonal variation [40,41]. Even though some regions in the northern part of Niger have an average wind speed of over $5 \mathrm{~m} / \mathrm{s}$ at a $10-\mathrm{m}$ height, the remaining major part experiences a relatively low wind speed of about $4 \mathrm{~m} / \mathrm{s}[12,18]$. Thus, electricity generation from wind is not taken into account in this study. On the other hand, the conventional electricity supply considered is from coal and diesel and not from natural gas since the latter is assumed to be unavailable in Niger [20]. The following section describes the details of the $\mathrm{RE}$ and conventional power supply model.

\section{The grid-tied PV system}

In order to obtain the specific energy yield of a grid-tied PV system, the approach indicated in [42] is used as follows:

$$
\begin{aligned}
P_{\mathrm{PV}, s}= & \frac{G_{t}}{1000 \mathrm{~W} / \mathrm{m}^{2}} \\
& \cdot P_{p}\left[+\alpha\left(\frac{G_{t}}{18 \mathrm{~W} / \mathrm{m}^{2}}+\left(T_{A}-20\right)\right)\right]
\end{aligned}
$$

where $P_{\mathrm{PV}, s}$ denotes the area-specific power of the PV module $\left[\mathrm{W} / \mathrm{m}^{2}\right] ; G_{t}$ the total radiation on the inclined surface $\left[\mathrm{W} / \mathrm{m}^{2}\right], P_{p}$ the peak power of the PV module $\left[\mathrm{W} / \mathrm{m}^{2}\right]$, and $\alpha$ represents the temperature coefficient and $T_{A}$ the ambient temperature $\left[{ }^{\circ} \mathrm{C}\right]$.

The efficiency of the inverter used to convert the DC power to AC power in Eq. (9) can be determined from

$$
\eta_{i}=\frac{p}{p+p_{0}+k \cdot p^{2}}
$$

where $\eta_{i}$ is the efficiency of the inverter, $p_{0}$ denotes the standby losses, $k$ is the rectifier constant, and $p$ is the ratio of the power output of the inverter to its rated power output. 


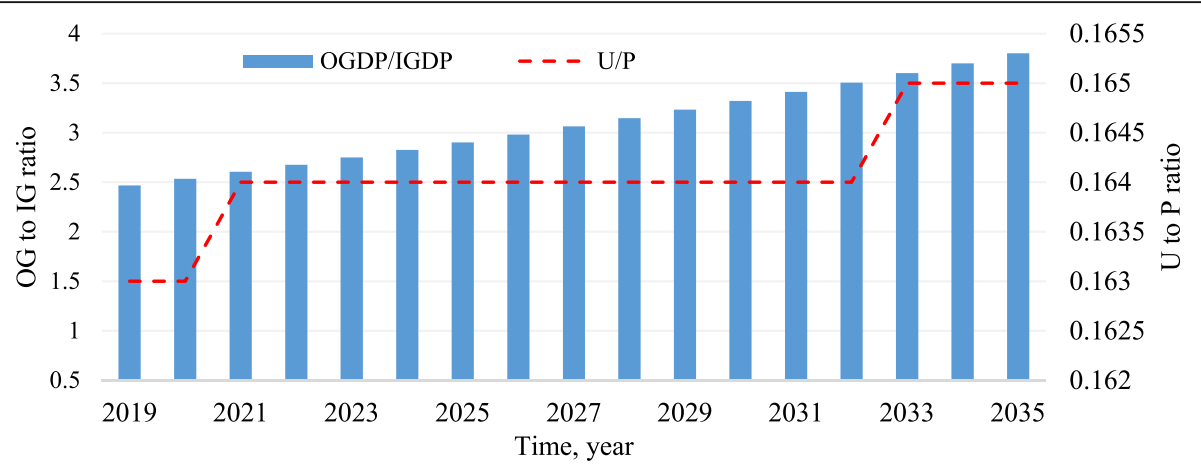

(a)

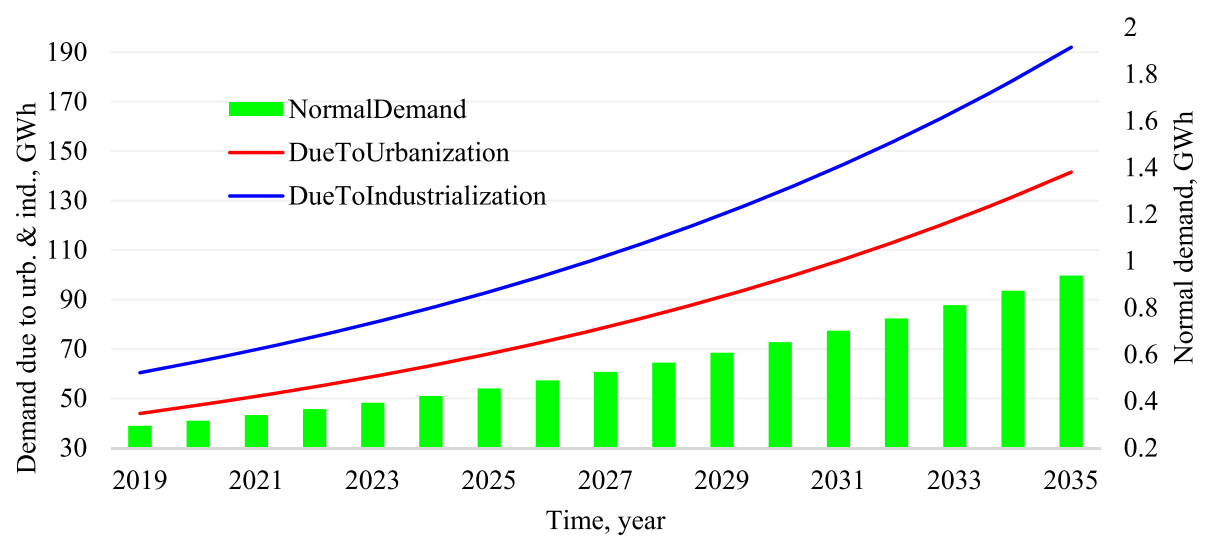

(b)

Fig. 8 a Ratio of urbanization to total population as well as other GDPs to industrial GDP and $\mathbf{b}$ net electricity demand trend contributed from urbanization, industrialization, and population growth (normal demand)

The net power output of a PV system can be calculated by considering the losses in the cables, bypass diodes, and loss due to dust on the PV modules as

$$
P_{n}=P_{\mathrm{PV}, s} \cdot \eta_{i} \cdot \eta_{\mathrm{AC}, c} \cdot \eta_{\mathrm{DC}, c} \cdot \eta_{d} \cdot \eta_{d i} \cdot \eta_{m}
$$

where $\eta_{\mathrm{AC}, c} \cdot \eta_{\mathrm{DC}, c} \cdot \eta_{d} \cdot \eta_{\mathrm{di}} \cdot \eta_{m}$ are the AC cable loss, the DC cable loss, the efficiency in the presence of dust on the module, the efficiency of bypass diodes, and the gross efficiency of the PV module specified by the manufacturer, respectively. Table 1 gives an overview of the coefficients and efficiencies used in the power calculation of the grid-tied PV module.

The PV power calculations based on Eqs. (9-11) were finally coded into the Anylogic. The PV power output is then simulated for a south-facing orientation with a tilt angle equal to the station's latitude where the solar radiation measurement is collected. The rated power capacity of the PV systems was initially set for $1 \mathrm{~kW}$ peak and extrapolated linearly for further output quantities during optimization. It is important to note that the hourly solar radiation data for Niamey are obtained from the Centre National d'Énergie Solaire (CNES) for 2015.
Reservoir hydropower and conventional power plants

The hourly available electrical energy $E_{h}$ from a given hydropower or conventional power plant can be determined using

$$
E_{h} \leq\left(P_{a}+P_{i}\right) \cdot C_{f} \cdot \Delta t
$$

where $P_{i}, P_{a}, C_{f}$ and $\Delta t$ denote the newly added power, the existing installed power, the capacity factor, and simulation time interval, respectively, which is $1 \mathrm{~h}$ in this case. The total power capacity is constrained by the maximum value $P_{m}$ as

$$
P_{a}+P_{i} \leq P_{h, m}
$$

Table 7 Reference and possible scenarios of potential future electricity demand projections

\begin{tabular}{llll}
\hline Parameter & Reference & C1 & C2 \\
\hline Ur & 0.039 & 0.047 & 0.039 \\
IGr & 0.089 & 0.089 & 0.108 \\
\hline
\end{tabular}




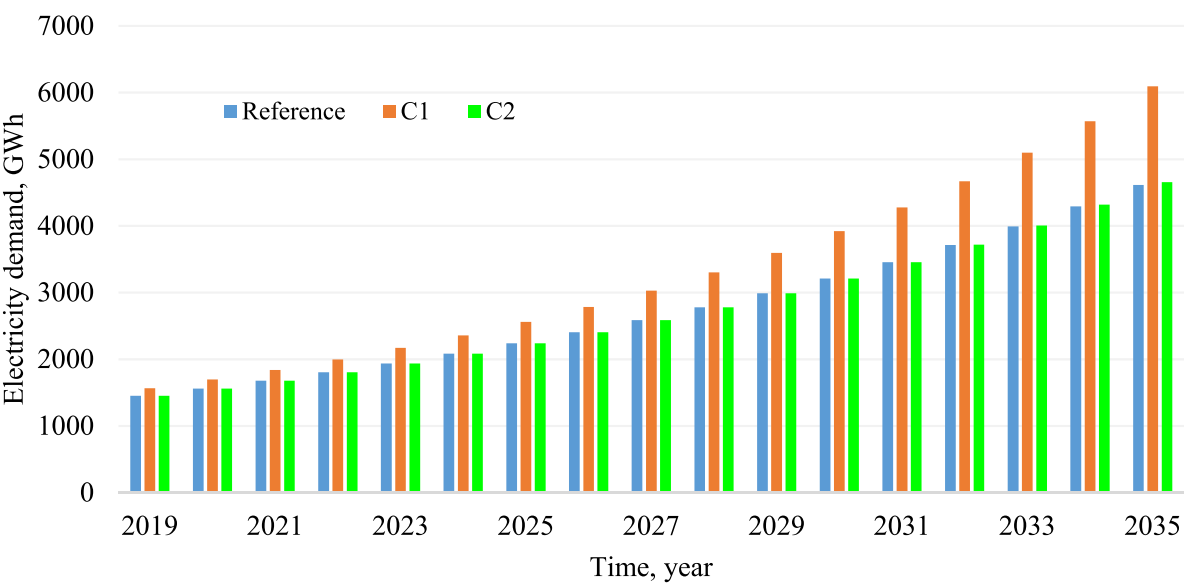

Fig. 9 The effect of urbanization and industrialization growth rate changes on the electricity demand projection

\section{Supply optimization}

The optimization problem is formulated based on the minimization of the hourly energy mismatch and the large variation of energy supply from the individual power generation technologies as

$$
\Omega=\int_{0}^{T}\left[\left(\alpha\left(S(t)_{t}-D_{a} \cdot L(t)\right)^{2}+\sum_{i=1}^{i=n} \beta_{i} S(t)_{i}^{2}\right) \mathrm{dt}\right]^{1 / 2}
$$

where $T$ is the length of the optimization time taken to be 1 year, $S(t)_{t}$ is the total electricity supply from $n$ renewable and conventional sources $S(t)_{i}, D_{a}$ is the average hourly load derived from the calibrated demand model, and $L(t)$ is the daily grid power profile normalized to unity taken from NEGELEC main power meter readings. The coefficients $\alpha$ and $\beta s^{\prime}$ are the weighting factors that determine the relative share of various power-generation technologies based on LCOE (SCOE) and electricity selling price $e_{p}$ and can be derived as

$$
\begin{aligned}
& \alpha=\frac{e_{p}}{\left[\sum\left(\mathrm{LCOE}_{i}\right)^{2}+e_{p}^{2}\right]^{1 / 2}} \\
& \beta_{i}=\frac{\mathrm{LCOE}_{i}}{\left[\sum\left(\mathrm{LCOE}_{i}\right)^{2}+e_{p}^{2}\right]^{1 / 2}}
\end{aligned}
$$

where the LCOE in Eq. (15) is the ratio of total life cycle cost to total lifetime energy production which is calculated as [38]:

$$
\mathrm{LCOE}=\frac{I-\sum_{t=1}^{T} d_{t} \gamma^{t} \cdot \alpha+\sum_{t=1}^{T} C_{t} \gamma^{t} \cdot(1-\alpha)-S \gamma^{T}}{E \cdot \sum_{t=1}^{T} \gamma^{t} \cdot x_{t}}
$$

where $\gamma$ represents the time value of money calculated based on the weighted average cost of capital, $r$, as $[\gamma=$

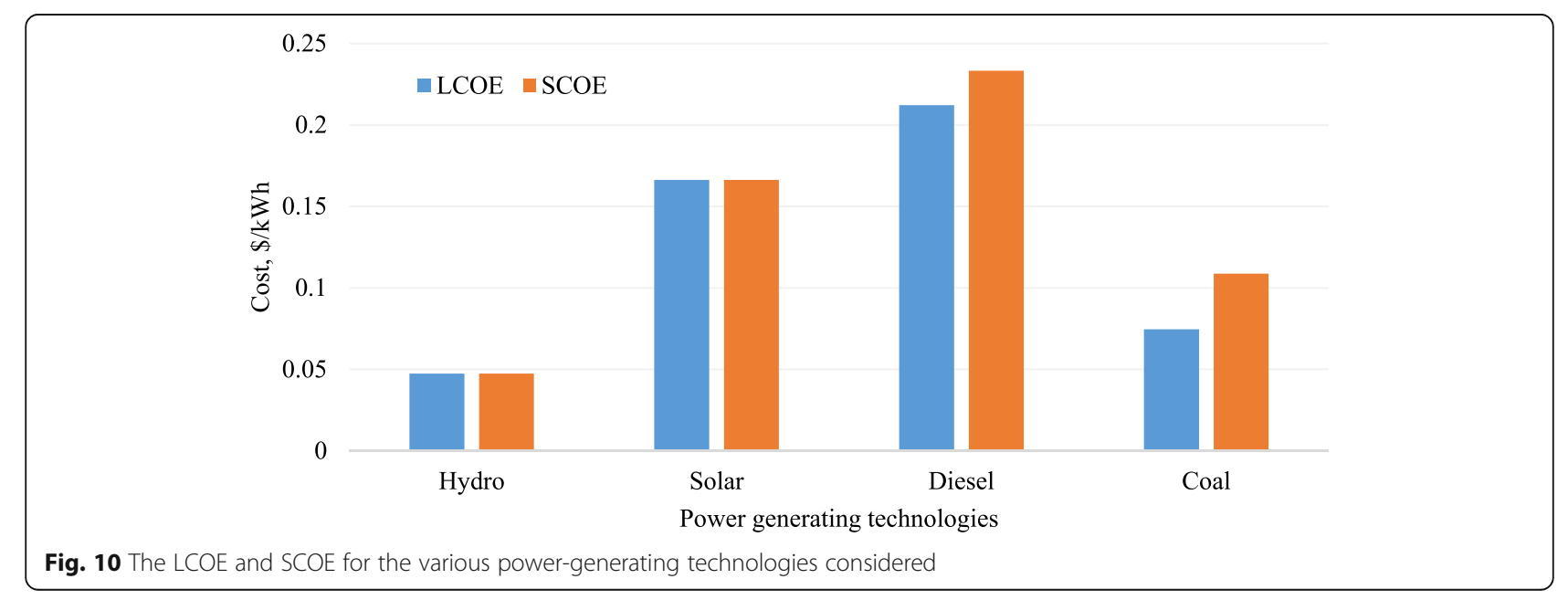




\section{Supply : Optimization}

\begin{tabular}{|c|c|c|}
\hline \multirow[t]{2}{*}{ Run } & \multirow[b]{2}{*}{ Current } & \multirow[b]{2}{*}{ Best } \\
\hline & & \\
\hline Iteration: & 500 & 490 \\
\hline Objective: & 134.717 & 134.717 \\
\hline \multicolumn{3}{|l|}{ Parameters } \\
\hline $\mathrm{HP}$ & 161.357 & 161.357 \\
\hline $\mathrm{CP}$ & 101.11 & 101.11 \\
\hline $\mathrm{DP}$ & 74 & 74 \\
\hline SP & 110 & 110 \\
\hline $\begin{array}{l}\text { Copy the best solution } \\
\text { to the clipboard }\end{array}$ & $>$ & copy \\
\hline
\end{tabular}

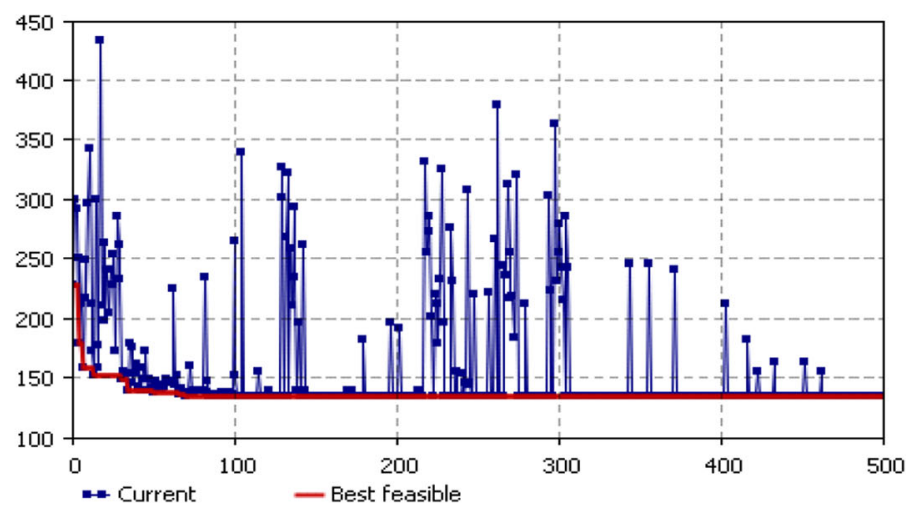

Fig. 11 Evolution of the optimization process in the Anylogic optimizer

$1 /(1+r)]$. The coefficients $I, S, \alpha, E, T, d_{t}, C_{t}$, and $x_{t}$ represent the initial investment, the salvage value of the technology at the end of the project, the corporate tax rate, the energy produced, the lifetime of the project, the depreciation rate, the operating cost, and the system degradation in year $t$, respectively. In the LCOE estimates for this work, the productive capacity remains undiminished for the various power-generation technologies. The weighted average cost of capital and corporate tax rate are also assumed to be 0.08 and 0.0 , respectively. The remaining parameter values used in the LCOE calculation are listed in Table $2[15,26,27]$.

On the other hand, the SCOE, which includes the costs incurred by the society from environmental and social points of view, can be given using [15]

$$
\mathrm{SCOE}=\mathrm{COCC}+\mathrm{COAP}
$$

where COCC and COAP are costs of climate change and air pollution.

Table 3 illustrates the $\mathrm{CO}_{2}$ emission rates for the various power-generating technologies considered in this study [28]. Of all technologies, coal-based power generation contributes largely towards global warming emission and air pollution.

The COCC in Eq. (17) is calculated based on a carbon $\operatorname{tax}$ that lays a proportional price on fossil fuels

Table 8 Settings for parameter variation experiment

\begin{tabular}{lllll}
\hline LCOE & Ref. & Min & Max & Step size \\
\hline Hydro & 0.0474 & 0.02 & 0.06 & 0.003 \\
Solar & 0.1663 & 0.1 & 0.22 & 0.009 \\
Diesel & 0.2121 & 0.2 & 0.31 & 0.008 \\
Coal & 0.0746 & 0.06 & 0.10 & 0.003 \\
\hline
\end{tabular}

according to their carbon content. The COAP also varies owing to the presence of different pollutants in fossil fuels. Due to the absence of valid data for hydropower's emission and air pollution cost, the SCOE is calculated for coal and diesel power generation. Additionally, the solar generation is assumed clean and hence no associated emission and air pollution costs should be considered. Table 4 gives an overview of these costs based on the indications given in $[15,43,44]$.

\section{Results and discussions}

In the first section, Niger's future electricity demand estimate derived from the system dynamic model is discussed. This is followed by a second section that depicts the supply optimization process based on LCOE and SCOE. A final section briefly discusses the $\mathrm{CO}_{2}$ emission reduction potential from the share of RE.

\section{Electricity demand estimate}

Niger's electricity demand for 2019-2035 is forecasted using the proposed electricity demand model that anticipates future changes based on its influencing factors. The trend of the influencing factors, namely GDP, population, urbanization, and industrialization, is explained below.

The annual average industrial and GDP growth rate in Niger from $2000-2017$ are taken as $9 \%$ and $12 \%$, respectively [4]. However, Niger's economic growth might increase driven mainly by mining and oil refining activities [1]. As a result, the economic growth rate may vary in the future. This variation is taken into consideration for the projection period from 2019 to 2035 . The average birth and mortality rate in the country was about $4.8 \%$ and $1 \%$ between 2000 and 2017. Although the population growth rate might slightly decrease according 


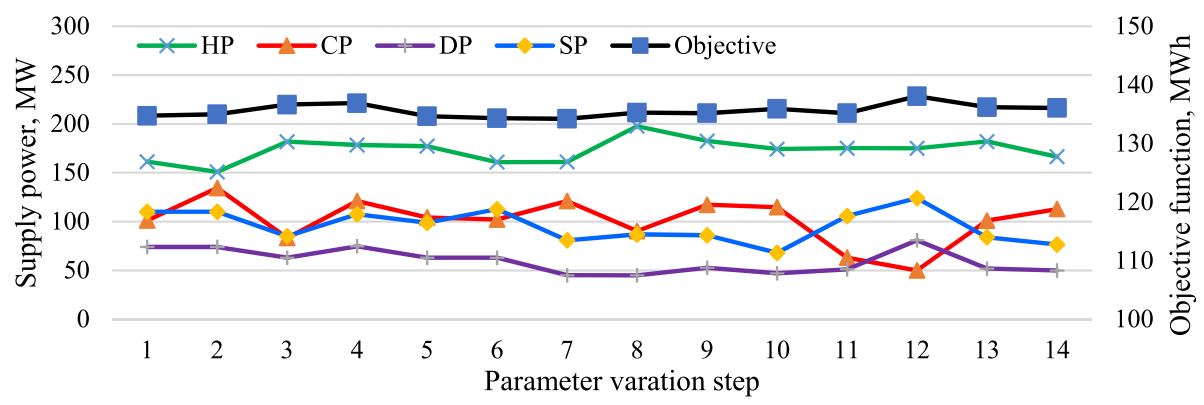

Fig. 12 Sensitivity analysis in supply optimization

to the observed $7.8 \%$ decline in total fertility in Africa from 2005 to 2015 [23], this small change is negligible and it is assumed that the birth and death rate values remain constant for the demand projection period.

Similar to other developing countries, the migration rate from Niger is expected to increase from $0.05 \%$ to $0.1 \%$ between 2030 and 2050 [45]. The annual average urbanization growth rate amounted to about 3.9\% for 2000-2017 [4], and the same rate is assumed for the electricity demand projection period of 2019-2035.

Before simulating the aforementioned scenarios, the electricity demand model needs to be calibrated and validated against the historical trend of electricity consumption in Niger. The procedure aims to minimize the mean square error (MSE) between the simulation output and historical data. Table 5 gives the calibrated variables and their associated values during the calibration process of the electricity demand model that are depicted in Fig. 6.

Figure 7 compares the calibrated electricity demand model output with the historical data and the error between them. As can be seen from Fig. 7, the calibrated model follows the historical trend of electricity demand over the years from 2000 to 2014. The MSE of calibration that is found at $1.66 \mathrm{kWh}$ also validates the capability of the model for estimating the future electricity demand under the given values of the influencing factors.

The projected electricity demand between 2019 and 2035 is illustrated in Table 6. The electricity demand shows an annual average growth rate of $7.5 \%$ during this

Table 9 Optimum values of the various power-generating technologies for the reference and the considered scenarios

\begin{tabular}{llll}
\hline Scenario & Reference & C1 & C2 \\
\hline Hydropower, MW & 161.40 & 177.43 & 181.21 \\
Coal power, MW & 101.10 & 129.73 & 117.54 \\
Diesel power, MW & 74.00 & 74.00 & 74.04 \\
PV, MW & 110.00 & 112.00 & 113.05 \\
Average annual demand, GWh & 3213.75 & 3244.79 & 3719.63 \\
\hline
\end{tabular}

period. Table 6 also indicates 1.64- and 2.21-fold increases in population and GDP between 2019 and 2035.

Figure 8a shows the relative trend of industrial GDP and urbanization. The contribution towards the total electricity demand because of population growth (normal demand), urbanization, and industrialization is illustrated in Fig. 8b. The ratio of the GDP to the industrial GDP is increasing at a slow pace. This means that Niger's economy is not dominated by manufacturing and/or processing industries. The small and gradually increasing industrial GDP observed is due to the mining sector that has been in place for a long time. It is possible to see from Fig. 8b that the extent of industrial GDP influence on the electricity demand is much more than the urbanization effect. This is because the urbanization progress is slow (Fig. 8a). It is also important to note that the demand given in Fig. $8 \mathrm{~b}$ is the net demand for each year based on the change in population, urbanization, and industrialization.

All of the aforementioned factors affecting electricity demand are not fixed and can change following a policy direction from the government. What follows is a scenario of possible anticipated future changes regarding urbanization and industrialization. Two scenarios (C1 and $\mathrm{C} 2$ ) are intended for analyzing their impact on the electricity demand in relation to a reference case presented earlier. The reference and what-if scenarios are given in Table 7.

In Table 7, the urbanization growth rate in $\mathrm{C} 1$ and the industrialization in $\mathrm{C} 2$ are allowed to vary by $20 \%$ from the reference scenario. When considering the electricity demand trend in Fig. 9, it is possible to observe that C2 does not change much compared to the reference scenario, but $\mathrm{C} 1$ shows a significant change. A stronger effect of urbanization rate changes on the electricity demand than the industrialization has also been indicated in the literature [3, 6-8].

\section{Supply optimization}

The following valid assumptions are taken into consideration for the supply optimization: 


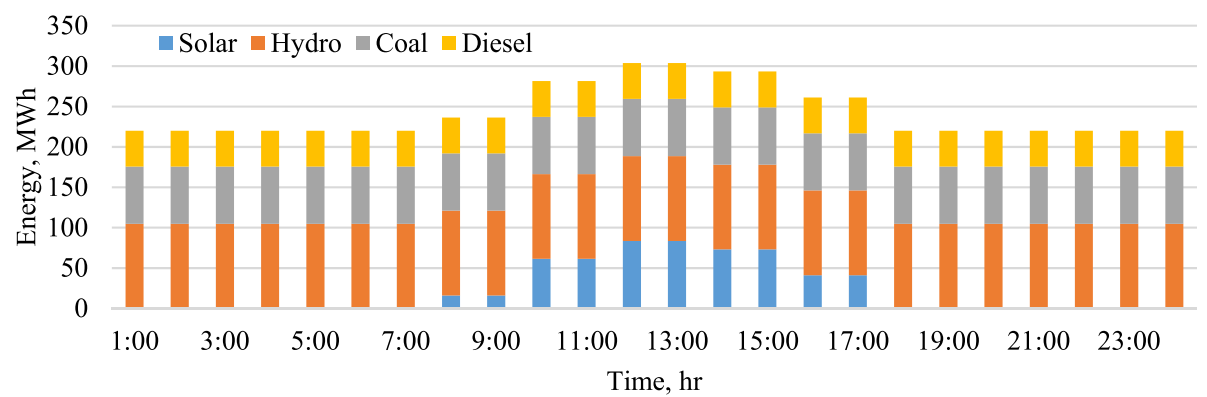

(a)

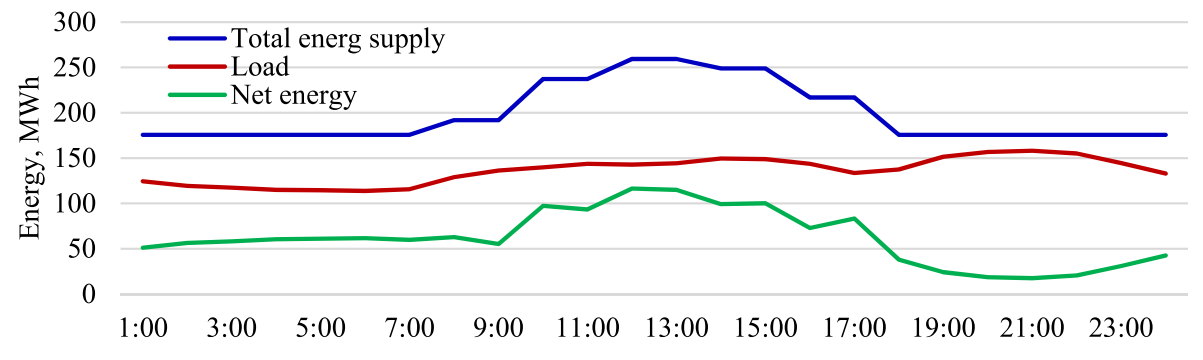

Time, hr

(b)

Fig. 13 Simulation of a typical day in the wet season that shows $\mathbf{a}$ energy supply and $\mathbf{b}$ demand and supply trend in 2030

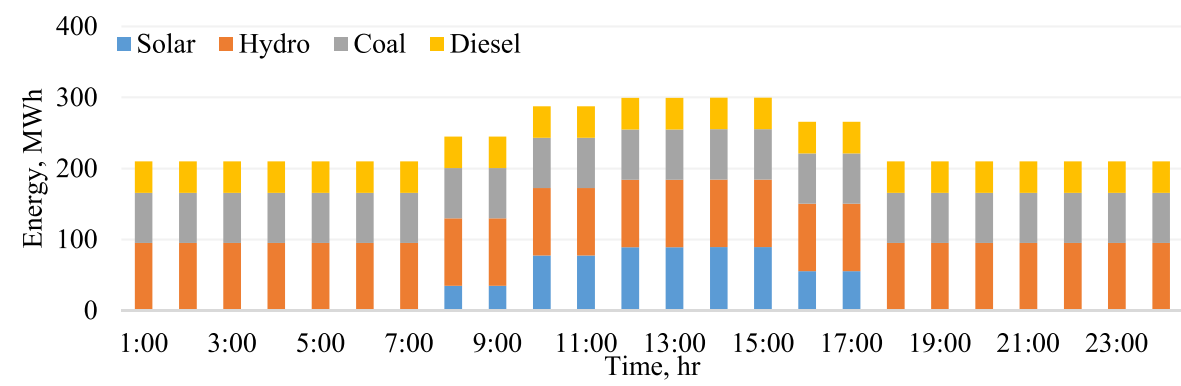

(a)

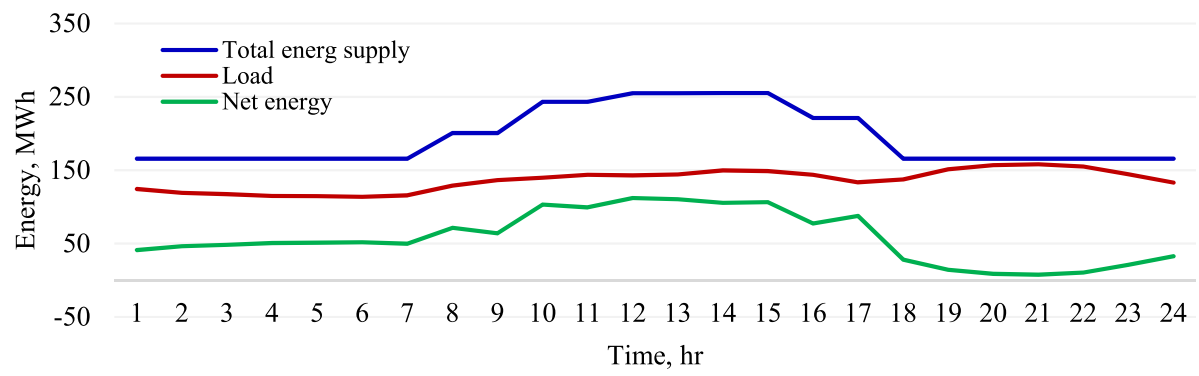

(b)

Fig. 14 Simulation of a typical day in the dry season that shows a energy supply and $\mathbf{b}$ demand and supply trend in 2030 


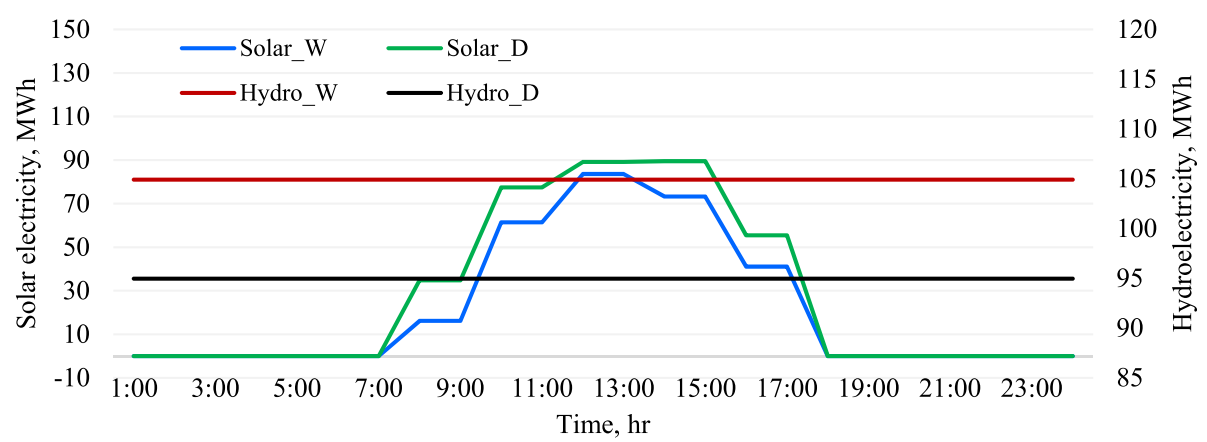

Fig. 15 Dry and wet season complementary nature of solar and hydropower

- As discussed in Section 1, Niger's heavy reliance on imported electricity from Nigeria stretched to about $86.5 \%$ in 2017 . Since the average electricity purchase price from Nigeria is cheap at about $0.044 \$ / \mathrm{kWh}$, it is not feasible to completely remove this imported electricity. Instead, a policy should aim at a gradual decrease of this large share to ensure energy security in the country (due to reasons given in the introductory part of this paper). Thus for supply optimization, a $40 \%$ decrease in the share of imported electricity is considered.

- The existing $140 \mathrm{MW}$ from fossil fuels is also included in the supply optimization procedure. The existing and newly introduced power plants constitute an optimal mix of energy supply from conventional and RE sources that will cover the removed imported energy and the added energy demand (due to population, urbanization, and industrialization).
- The electricity output from hydropower plants in the dry season is allowed to vary from its rated power output by an average value of $28.5 \%$.

- In the optimization procedure, the total hydropower potential is set to be $400 \mathrm{MW}[17,18]$, whereas the coal, diesel, and solar power are assumed unlimited to meet the country's energy demand until 2035.

The LCOE and SCOE of the various power-generation technologies that are the basis for setting the weighting factor in the objective function of the optimization problem are given in Fig. 10. As for the LCOE, the most economical choices for electricity generation come from hydropower and coal with an LCOE of 0.0474 and $0.0746 \$ / \mathrm{kWh}$, respectively. On the other hand, the SCOE showed that power generation from coal is associated with higher cost from pollution and environment aspects.

\section{Supply : Optimization}
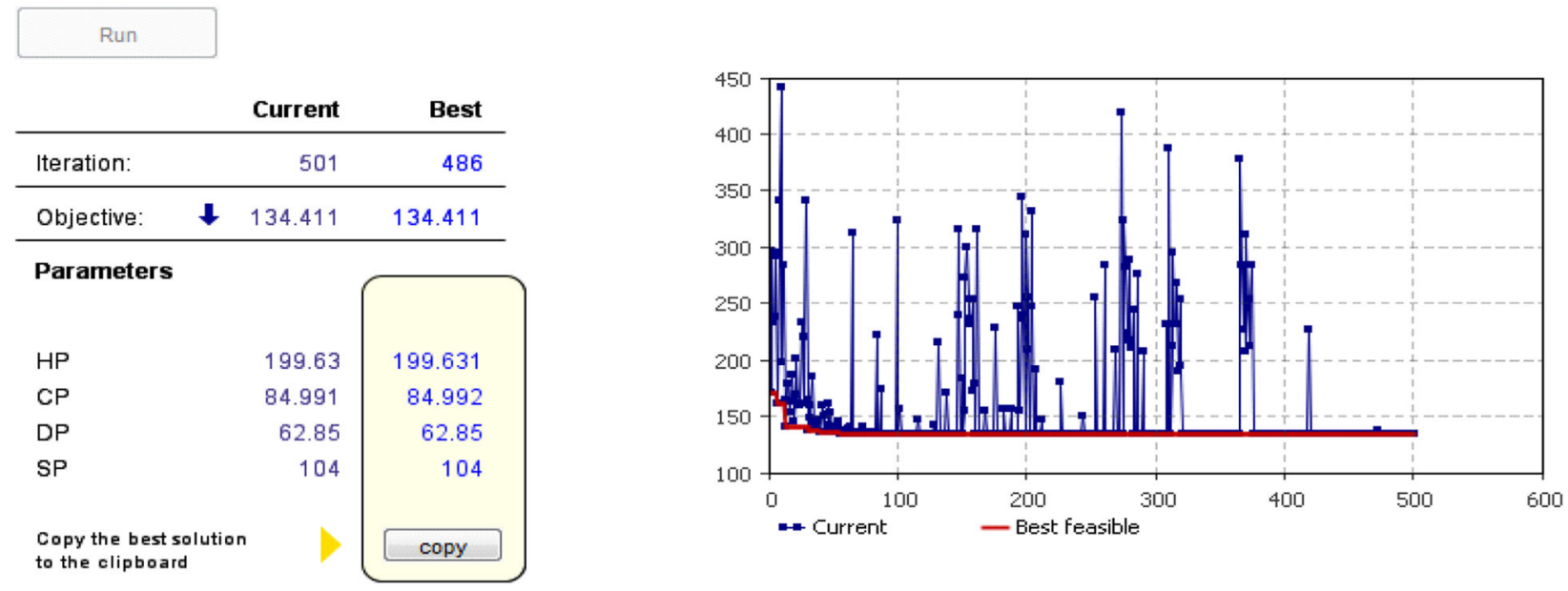

Fig. 16 SCOE-based optimization implementation in the Anylogic optimizer 
The supply optimization based on the LCOE is discussed first, and later, this result is compared with the SCOE-based optimization approach.

Figure 11 depicts the states of the objective function and the optimal variables while the simulation is running. The Anylogic optimizer is configured to run for 500 iterations in search of the optimal solution. It gives out the "best feasible" and "current" solutions. The optimizer also keeps a record of the frequency of occurrences of the best optimal solution out of the maximum assigned iteration (490 for the case illustrated in Fig. 11). Finally, the optimizer allows for copying of the best optimal parameter values to transfer them back to the simulation environment for further analysis.

A sensitivity analysis to analyze the effect of variation of the LCOE values on the optimization result based on capacity factor, fuel costs, and projected cost reduction changes is carried out using the experiment setting depicted in Table 8.

The result of the effect of the LCOE variation on the optimal values is illustrated in Fig. 12. There is only a $2.9 \%$ change observed in objective function values as the LCOEs vary from the minimum to the maximum values. This is because the weight values of the objective function do not depend on the individual LCOE but on their relative magnitude as given in Eq. (15). For the same reason, it is also possible to notice that there is a relatively high variation in the optimal values for hydro and coal power plants compared to diesel and solar PV.

The LCOE-optimized grid that fulfills the projected demand in 2030 for the reference and the two scenarios $\mathrm{C} 1$ and $\mathrm{C} 2$ is depicted in Table 9. It is important to note that for $\mathrm{C} 1$ and $\mathrm{C} 2$, the reference case is used as the starting value during the optimization process. From Table 9, it is evident that the method employed resulted in a $60.78 \%$ share of renewable energy sources, including hydropower for the reference case. The PV share in the total RE is about $24.63 \%$. It is also possible to see that the contribution from diesel is the lowest accounting for only $16.57 \%$ of the total power. In addition, the diesel contribution remains the same in all the cases due to its relatively high LCOE value. Moreover, this trend of assigning preference based on the LCOE explains the relative variation of optimal values for the various power-generating technologies.

The daily trend of the demand and the supply of energy for the reference case on a typical day in the wet season (August 15 in 2030) is shown in Fig. 13. It is possible to see from Fig. $13 \mathrm{~b}$ that the optimal supply guarantees the load constraint placed on the optimization during the whole day.

Similarly, the simulation of the energy output for the various power-generating technologies and a typical dry season (January 15 in 2030) is depicted in Fig. 14. The solar output is relatively uniform when compared to its yield in the wet season demonstrated in Fig. 13. As indicated in Fig. 14b, the optimal power configuration balances the energy demand despite the observed decrease in hydropower in the dry season.

The complementary nature of solar and hydropower is evident from Fig. 15. In dry seasons, the electricity from hydropower decreases from the wet season value of 104.91 MWh to $94.97 \mathrm{MWh}$. On the other hand, the solar PV yield increases from its worst day in the wet season from $551.26 \mathrm{MWh}$ to $692.842 \mathrm{MWh}$ for the best day in the dry season.

It is important to note that the actual solar energy supply from the optimized power plant is expected to be higher than that suggested in Fig. 13 and Fig. 14. Due to the absence of measured data, the solar PV output is simulated for Niamey, which receives the lowest solar radiation compared to other regions in Niger, as demonstrated in Fig. 4.

Finally, the consideration of the SCOE as a basis for setting the optimization weights reveals some interesting points. The results given in Fig. 16 show that the contribution from coal and diesel power is negligible in comparison to hydropower and solar power generation. This means that when all costs, including costs borne by the society and environment, are taken into account, a generation from traditional fuels should be avoided. However, given the urgent need for the economic development of Niger, energy affordability should have a priority in designing the optimal mix of energy supply in the grid. As technological advancements make power generation from renewables competitive, the LCOEbased optimal design tends to result in a solution that resembles the SCOE given in Fig. 16.

Another point is that in the years beyond 2030, where the electricity demand is expected to double, the most preferred hydropower will be fully utilized. Thus, Niger should start exploiting its solar as well as conventional sources intensively to balance its long-term energy demand.

\section{Greenhouse gas emissions}

The total greenhouse gas (GHG) emission can be calculated by considering the contribution from each energy source to electricity production based on the data given in Table 3 as

$$
\mathrm{CO}_{2, T}=\frac{g_{1} \cdot E_{H}+g_{2} \cdot E_{S}+g_{3} \cdot E_{C}+g_{4} \cdot E_{d}}{1000}
$$

where $\mathrm{CO}_{2}, T$ is the total annual carbon dioxide generated $\left(T \mathrm{CO}_{2 \mathrm{eq}}\right), E_{H}, E_{S}, E_{C}$, and $E_{D}$ are the annual energy yields (MWh) from hydropower, grid-tied PV, and coal and diesel power plants, and $g 1-g 4$ are the equivalent 
GHG emissions due to the various power generating technologies, as given in Table $3\left(\mathrm{~kg} \mathrm{CO} \mathrm{CO}_{2 \mathrm{eq}} / \mathrm{MWh}\right)$. Thus, for example, the LCOE-based optimized power supply system in 2030 results in 865,676-1,233,674 $\mathrm{TCO}_{2 \text { eq }}$ emissions. Similarly, the SCOE-based supply optimization reduces the total GHG emission to the range $730,083-1,094,811 \mathrm{TCO}_{2 \mathrm{eq}}$.

\section{Conclusions}

In this work, efforts have been made to address the future electricity demand and supply in Niger in an integrated and holistic approach. The approach used is a system dynamic model to anticipate future electricity demand changes as a result of population growth, urbanization progress, and industrial development. Reference case and probable scenarios were simulated to obtain the projected electricity demand and their associated renewable energy transition pathways for 20192035. Before simulating the aforementioned scenarios, the electricity demand model was calibrated and validated against the historical trend of electricity consumption in the country. The calibration process minimized the MSE between the simulation output and historical data. The MSE of calibration, that is found to be $1.66 \mathrm{kWh}$, validated the capability of the model in estimating the future electricity demand under the given and assumed influencing factor values. From the calibrated model, it was discovered that a relatively small change in industrialization from the reference case has only a negligible short-term impact. On the other hand, a $20 \%$ change in urbanization growth rate will result in a $22 \%$ increase of the electricity demand in 2030.

Preceding the electricity demand projection, an optimal energy supply to balance the demand was suggested and implemented. In an attempt to realize the most beneficial optimal mix of electricity generation, an SCOE is formulated as the LCOE plus the cost of climate change and air pollution. The SCOE is then used as a basis for setting the performance criteria of supply optimization. As a result, a power grid contributed from a share of $44.22 \%$ hydro, $23.04 \%$ grid-tied PV, $18.83 \%$ coal, and $13.92 \%$ diesel was identified for 2030 according to their relative SCOE values. When compared with the GHG emission, the SCOE-based optimized grid results in $11.26-15.66 \%$ less emission than the LCOE-based optimized grid during the same period. Moreover, the optimization highlights the need to intensively use the conventional and solar potential in Niger in the near future to sustain the ever-increasing energy demand. The proposed grid mix also lessens the country's actual electricity import dependency that currently poses serious energy security issues such as electricity price volatility and supply reliability. Likewise, the proposed strategy helps guide the RE transition pathway in the country with the maximum use of solar PV.

This outcome of the study could help formulate innovative policy pathways for a sustainable energy supply in Niger. There is a growing trend of recognition for developing reliable and adequate electricity supply schemes that can balance the country's future demand. However, a successful realization of the recognition needs an adequate understanding of the underlying relationships among the demand and its influencing factors. A notable requirement is the development of a framework that can link demand and supply. The developed framework needs also to consider the role of an optimized electricity generation mix for the sake of sustainable development (urbanization and industrialization) and climate change goals. Unfortunately, the optimized mix grid, including the alternative energy sources, is not yet considered as a viable energy supply scheme in Niger. This work gives evidence that future RE transition pathways are competitive both from an economical and societal point of view.

\section{Abbreviations \\ CNES: Centre National d'Énergie Solaire; COAP: Cost of air pollution; COCC: Cost of climate change; GHG: Greenhouse gases; LCOE: Levelized cost of electricity; MSE: Mean square error; NIGELEC: Société Nigérienne d'Electricité; PV: Photovoltaics; RE: Renewable energy; SCOE: Society's cost of electricity

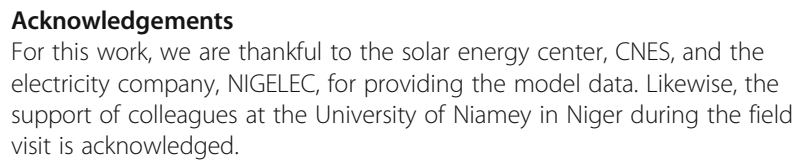
electricity company, NIGELEC, for providing the model data. Likewise, the support of colleagues at the University of Niamey in Niger during the field visit is acknowledged.

\section{Authors' contributions \\ All authors contributed for the modeling and development of the manuscript. All authors read and approved the final manuscript.}

\section{Funding}

This research was funded by the German Federal Ministry of Education and Research (BMBF) via Project Management Agency DLR.

Availability of data and materials

Data can be shared by requesting the corresponding author.

Ethics approval and consent to participate

Not applicable

Consent for publication

Not applicable

\section{Competing interests}

The authors declare that they have no competing interests.

\section{Author details}

${ }^{1}$ Institute for Technology and Resources Management in the Tropics and Subtropics (ITT), TH Köln (University of Applied Science), Betzdorfer Strasse 2, 50679 Cologne, Germany. ${ }^{2}$ Institute of Technology, Addis Ababa University, King George VI Street, Addis Ababa, Ethiopia. 
Received: 6 March 2019 Accepted: 19 July 2019

\section{Published online: 29 July 2019}

\section{References}

1. Economic and Social Development Plan (ESDP) (2017) Niger renaissance, https://www.nigerrenaissant.org/sites/default/files/pdf/pdes-summary.pdf. Accessed 21 Feb 2019.

2. Trotter PA, McManus MC, Maconachie R (2017) Electricity planning and implementation in sub-Saharan Africa: a systematic review. Renewable and Sustainable Energy Reviews 74:1189-1209. https://doi.org/10.1016/j.rser.201 7.03.001

3. Sadorsky P (2013) Do urbanization and industrialization affect energy intensity in developing countries? Energy Economics 37:52-59. https://doi. org/10.1016/j.eneco.2013.01.009

4. The World Bank (2019) Country data Niger, https://data.worldbank.org/ country/niger. Accessed 21 Feb 2019.

5. United Nations Economic Commission for Africa (UNECA) (2018) Accelerating SDG 7 achievement, policy briefs in support of the first SDG7 review at the UN high-level political forum, https://sustainabledevelopment. un.org/content/documents/17565PB18.pdf. Accessed 06 Nov 2018.

6. Yu S, Zhu K (2012) A hybrid procedure for energy demand forecasting in China. Energy 37(1):396-404. https://doi.org/10.1016/j.energy.2011.11.015

7. Li K, Lin B (2017) An application of a double bootstrap to investigate the effects of technological progress on total-factor energy consumption performance in China. Energy 128:575-585. https://doi.org/10.1016/j. energy.2017.04.044

8. Shahbaz M, Salah Uddin G, Ur Rehman I, Imran K (2014) Industrialization, electricity consumption and $\mathrm{CO} 2$ emissions in Bangladesh. Renewable and Sustainable Energy Reviews 31:575-586. https://doi.org/10.1016/j.rser.2013.12.028

9. Franco S, Mandla VR, Ram Mohan Rao K (2017) Urbanization, energy consumption and emissions in the Indian context a review. Renewable and Sustainable Energy Reviews 71:898-907. https://doi.org/10.1016/.rser.2016.12.117

10. Bakirtas T, Akpolat AG (2018) The relationship between energy consumption, urbanization, and economic growth in new emerging-market countries. Energy 147:110-121. https://doi.org/10.1016/j.energy.2018.01.011

11. Zhao P, Zhang M (2018) The impact of urbanisation on energy consumption: A 30-year review in China. Urban Climate 24:940-953. https:// doi.org/10.1016/j.uclim.2017.11.005

12. Energy Charter (2015) The energy sector of Niger: perspectives and opportunities, https://energycharter.org/fileadmin/DocumentsMedia/ Occasional/Niger_Energy_Sector.pdf. Accessed 21 Feb 2019.

13. NIGELEC (Société Nigerienne d'Electricité) (2018) Database of state utility company for electricity in Niger, Niamey, Niger

14. Monyei CG, Adewumi AO, Obolo MO, Sajou B (2018) Nigeria's energy poverty: Insights and implications for smart policies and framework towards a smart Nigeria electricity network. Renewable and Sustainable Energy Reviews 81:1582-1601. https://doi.org/10.1016/j.rser.2017.05.237

15. Nigerian Economic Summit Group and Heinrich Böll Stiftung (2017) Comparison of costs of electricity generation in Nigeria, https://ng.boell.org/ sites/default/files/true_cost_of_power_technical_report_final.pdf. Accessed 21 Feb 2019.

16. ECOWAS (2019) Energy ministries in Niger database, http://www.assemblee.ne/. Accessed 21 Feb 2019

17. Poyry Energy and ECOWAS Centre for Renewable Energy and Energy Efficiency (ECREEE) (2017) Niger Country Report- GIS Hydropower Resource Mapping and Climate Change Scenarios for the ECOWAS Region, http:// www.ecowrex.org/system/files/country_report_10_niger.pdf. Accessed 21 Feb 2019

18. IRENA (2013a) Niger renewables readiness assessment, https://www.irena. org/-/media/Files/IRENA/Agency/Publication/2013/RRA_Niger.pdf, Accessed 21 Feb 2019.

19. Solargis (2019) Solar resource maps of Niger, https://solargis.com/ maps-and-gis-data/download/niger Accessed 21 Feb 2019.

20. IRENA (2013b) West African power pool: planning and prospects for renewable energy, https://www.irena.org/documentdownloads/ publications/wapp.pdf. Accessed 21 Feb 2019

21. Wagner A (2015) Photovoltaik Engineering. Springer Verlag Berlin, Heidelberg

22. Roumpakias E, Zogou O, Stamatelos A (2015) Correlation of actual efficiency of photovoltaic panels with air mass. Renewable Energy 74:70-77. https:// doi.org/10.1016/j.renene.2014.07.051
23. Notton G, Lazarov V, Stoyanov L (2010) Optimal sizing of a grid-connected PV system for various PV module technologies and inclinations, inverter efficiency characteristics and locations. Renewable Energy 35(2):541-554. https://doi.org/10.1016/j.renene.2009.07.013

24. Topcu I, Ülengin F, Kabak Ö, Isik M, Unver B, Ekici SO (2018) The evaluation of electricity generation resources: the case of Turkey. Energy. https://doi. org/10.1016/j.energy.2018.10.126

25. Kanitkar T, Banerjee R, Jayaraman T (2018) An integrated modeling framework for energy economy and emissions modeling: a case for India. Energy. https://doi. org/10.1016/j.energy.2018.11.025

26. IRENA (2018) Renewable power generation costs in 2017 International Renewable Energy Agency, Abu Dhabi. https://www. irena.org/-/media/Files/IRENA/Agency/Publication/2018/Jan/IRENA_2 017_Power_Costs_2018.pdf. Accessed 06 Nov 2018.

27. International Energy Agency (IEA) (2015) Projected costs of generating electricity, https://www.oecd-nea.org/ndd/pubs/2015/7057-proj-costselectricity-2015.pdf Accessed 21 Feb 2019.

28. IPCC (2014). Annex II: Metrics \& Methodology, Mitigation of Climate Change, https://www.ipcc.ch/site/assets/uploads/2018/02/ipcc_wg3_ar5_annex-ii.pdf, Accessed 21 Feb 2019.

29. He Y, Zheng $Y, X u$ Q (2019) Forecasting energy consumption in Anhui province of China through two Box-Cox transformation quantile regression probability density methods. Measurement. https://doi.org/10.1016/j. measurement.2019.01.008

30. Al-Musaylh MS, Deo RC, Adamowski JF, Li Y (2018) Short-term electricity demand forecasting with MARS, SVR and ARIMA models using aggregated demand data in Queensland, Australia. Advanced Engineering Informatics 35:1-16. https://doi.org/10.1016/j.aei.2017.11.002

31. Bedi J, Toshniwal D (2019) Deep learning framework to forecast electricity demand. Applied Energy 238:1312-1326. https://doi.org/10.1016/j. apenergy.2019.01.113

32. Torrini FC, Souza RC, Cyrino Oliveira FL, Moreira Pessanha JF (2016) Long term electricity consumption forecast in Brazil: a fuzzy logic approach. Socio-Economic Planning Sciences 54:18-27. https://doi. org/10.1016/j.seps.2015.12.002

33. Yang A, Li W, Yang X (2018) Short-term electricity load forecasting based on feature selection and Least Squares Support Vector Machines. KnowledgeBased Systems. https://doi.org/10.1016/j.knosys.2018.08.027

34. He Y, Jiao J, Chen Q, Ge S, Chang Y, Xu Y (2017) Urban long term electricity demand forecast method based on system dynamics of the new economic normal: the case of Tianjin. Energy 133:9-22. https://doi.org/10.1016/j.energy.2017.05.107

35. Morcillo JD, Franco CJ, Angulo F (2018) Simulation of demand growth scenarios in the Colombian electricity market: an integration of system dynamics and dynamic systems. Applied Energy 216:504-520. https://doi. org/10.1016/j.apenergy.2018.02.104

36. Smit S, Musango JK, Brent AC (2019) Understanding electricity legitimacy dynamics in an urban informal settlement in South Africa: a community based system dynamics approach. Energy for Sustainable Development 49: 39-52. https://doi.org/10.1016/j.esd.2019.01.004

37. Khraief N, Shahbaz M, Mallick H, Loganathan N (2018) Estimation of electricity demand function for Algeria: revisit of time series analysis. Renewable and Sustainable Energy Reviews 82:4221-4234. https:// doi.org/10.1016/j.rser.2016.11.106

38. International Energy Agency (IEA) (2011) Renewable energy markets and prospects by technology, https://www.iea.org/publications/freepublications/ publication/Renew_Tech.pdf. Accessed 21 Feb 2019.

39. Gebretsadik Y, Fant C, Strzepek K, Arndt C (2016) Optimized reservoir operation model of regional wind and hydro power integration case study: Zambezi basin and South Africa. Applied Energy 161:574-582. https://doi. org/10.1016/j.apenergy.2015.09.077

40. François B, Borga M, Creutin JD, Hingray B, Raynaud D, Sauterleute JF (2016) Complementarity between solar and hydro power: sensitivity study to climate characteristics in Northern-Italy. Renewable Energy 86:543-553. https://doi.org/10.1016/j.renene.2015.08.044

41. Schmidt J, Cancella R, Pereira AO (2016) An optimal mix of solar PV, wind and hydro power for a low-carbon electricity supply in Brazil. Renewable Energy 85:137-147. https://doi.org/10.1016/j.renene.2015.06.010

42. Paatero JV, Lund PD (2007) Effects of large-scale photovoltaic power integration on electricity distribution networks. Renewable Energy 32(2): 216-234. https://doi.org/10.1016/j.renene.2006.01.005 
43. World Bank and Ecofys (2018) State and trends of carbon pricing, https:// openknowledge.worldbank.org/bitstream/handle/10986/29687/9781464812 927.pdf? sequence=5\&isAllowed=y. Accessed 21 Feb 2019.

44. Machol B, Rizk S (2013) Economic value of U.S. fossil fuel electricity health impacts. Environment International 52:75-80. https://doi.org/10.1016/j. envint.2012.03.003

45. Campbell, M. (2008) The drivers of the levelized cost of electricity for utilityscale photovoltaics, SunPower Corporation, http://large.stanford.edu/ courses/2010/ph240/vasudev1/docs/sunpower.pdf. Accessed 21 Feb 2019.

\section{Publisher's Note}

Springer Nature remains neutral with regard to jurisdictional claims in published maps and institutional affiliations.

Ready to submit your research? Choose BMC and benefit from:

- fast, convenient online submission

- thorough peer review by experienced researchers in your field

- rapid publication on acceptance

- support for research data, including large and complex data types

- gold Open Access which fosters wider collaboration and increased citations

- maximum visibility for your research: over $100 \mathrm{M}$ website views per year

At $\mathrm{BMC}$, research is always in progress.

Learn more biomedcentral.com/submissions 